\title{
The Effect of a Midwife-Based Group Discussion Education on Sexual Dysfunction Beliefs in Rural Postmenopausal Women
}

This article was published in the following Dove Press journal: International Journal of Women's Health

\author{
Maryam Sasanpour' \\ Nezal Azh ${ }^{2}$ \\ Mahmoud Alipour ${ }^{3}$ \\ 'Student Research Committee, Qazvin \\ University of Medical Sciences, Qazvin, \\ Iran; ${ }^{2}$ Faculty of Nursing and Midwifery, \\ Qazvin University of Medical Sciences, \\ Qazvin, Iran; ${ }^{3}$ Faculty of Medicine, Qazvin \\ University of Medical Sciences, Qazvin, \\ Iran
}

\begin{abstract}
Introduction: Correcting sexual beliefs can affect women's sexual function. There are very limited interventional studies on correcting the sexual dysfunction beliefs in postmenopausal women living in rural areas. Therefore, the present study was carried out with the aim of investigating the effect of a midwife-based group education on sexual dysfunction beliefs in one group of rural postmenopausal women.
\end{abstract}

Methods: The present study was a quasi-experimental pre-post design without a control group. The study population included rural menopausal women who referred to rural health centers. The study sample consisted of 50 participants who have all received education program. The education was held in six group discussion sessions. The data gathering tool used in this study was the Sexual Dysfunctional Beliefs Questionnaire which was completed before and after the education. This questionnaire consists of 33 items and includes 6 subscales.

Results: The mean age of participants was 53.26 years. Approximately half of the participants $(48 \%)$ had primary education. The mean scores of sexual dysfunction beliefs before and after education were 114.58 and 58.56, respectively (p-value $<0.001$ ). The mean scores of sexual conersations, affection primacy, motherhood-related beliefs, sexual desire and pleasure as sin beliefs, age-related beliefs, and body image beliefs before intervention were 14.38, 21.38, 13.9, 23.64, $20.74,17.04$, respectively, and after intervention were $6.9,11.80,8.64,12.48,7.7,9.40$, respectively. Conclusion: Rural postmenopausal women had problems with sexual dysfunction beliefs. A midwife-based group discussion education on this matter had significantly improved the sexual dysfunction beliefs in them. Further studies are needed in this regard.

Keywords: education, group discussion, menopause, rural women, sexual function, promoting sexual health

\section{Quick Points}

1. Sexual dysfunction is addressed as a hidden epidemic in postmenopausal women.

2. Interventional studies on sexual dysfunction beliefs in postmenopausal women are limited.

3. Midwife-based group discussion education can significantly reduce the sexual dysfunction beliefs among rural postmenopausal women.

4. Midwives have an important role in rural women's health promotion.

\section{Introduction}

Menopause is a turning point in women's lifespan, and although it is a physiological process and a general event, it is not felt in the same way for all
Correspondence: Nezal Azh Faculty of Nursing and Midwifery, Qazvin University of Medical Sciences, Qazvin, Iran

Email nezalazh20@gmail.com 
women. ${ }^{1}$ Millions of women worldwide have reached menopause. $^{2}$ Women spend about one third of their lifespan at menopause, and taking care of the various dimensions of health in them is highly important. ${ }^{3}$ Several factors can affect the menopausal experience in women. ${ }^{1}$ Factors such as lifestyle, social support, income, and cultural factors are among the factors that can result in different menopausal experiences in rural and urban women. ${ }^{4}$ In 2018, Karma reported that the sexual life of rural postmenopausal women is significantly affected. ${ }^{5}$ Also, price in one qualitative study reported that rural women in Canada experienced significant complications after menopause. $^{2}$

Sex hormones in women will be changed during menopause. Estrogen and testosterone are two primary hormones that their blood levels decreased during menopause. ${ }^{6}$ This change will lead to significant changes in the body of postmenopausal women. Changes such as mood changes, sleep disturbances, a decrease in vaginal acidity, urinary incontinency and urinary tract infections, malaise in the genital area, a decrease in vaginal discharge and subsequent vaginal dryness, vaginal atrophy, and erratic menstruation are such changes can lead to sexual dysfunction in postmenopausal women. ${ }^{7,8}$ In some databases, sexual dysfunction is addressed as a hidden epidemic in postmenopausal women. ${ }^{6}$ Recently Jain et al reported that nearly $80 \%$ of post-menopausal women in India experienced sexual dysfunction. ${ }^{9}$ Another study in Italy in 2019 by Cagnacci et al reported that $70.6 \%$ of menopausal women experienced sexual dysfunction. ${ }^{10}$

Beyond hormonal changes in the body of postmenopausal women, one of the factors that can lead to sexual inefficiency in postmenopausal women is the sexual dysfunction beliefs of these women. ${ }^{11}$ Sexual dysfunctionbeliefs are defined as unrealistic and incorrect conceptions of sexual intercourses and responses that are accepted without being approved by scientific evidence. ${ }^{12}$ Sexual dysfunction can negatively affect women's conjugal relationships, psychological health, self-esteem, and quality of life. ${ }^{9}$ In one study in this regard, Nazarpour et al examined the sexual function and its relationship with their quality of life in menopausal women. The results of their study showed that women who had sexual dysfunction had a lower level of quality of life. ${ }^{13}$ Improving the sexual health of rural menopausal women can improve their sexual activity and, consequently, increase the quality of their lives. ${ }^{14}$ However, there are very limited interventional studies in order to correct the sexual dysfunction beliefs in postmenopausal women in rural areas. Therefore, the present study was carried out with the aim of investigating the effect of a midwife-based group discussion education on sexual dysfunction beliefs in rural postmenopausal women.

\section{Methods}

The present study was a quasi-experimental pre-post design without a control group, which was conducted in 2017-2018. The study population included rural menopausal women who referred to rural health centers in Khur and Biabanak County, Isfahan City. We had 50 menopause women in this center that were eligible for the study. All of them were invited to participate in our study.

The inclusion criteria for the study were the presence of a spouse, and passing at least 1 year from the last menstrual period. The exclusion criteria included artificial menopause, underlying diseases such as diabetes, hypertension in women and their husbands, or the application of drugs that affected their sexual function.

\section{Instruments}

Data were collected by a demographic questionnaire and the Nobre and Pinto-Gouveia Sexual Dysfunctional Beliefs Questionnaire (Female Version). For this purpose, the researcher asked women to participate in the study after attending to the center and introducing herself and the aims of the study.

The demographic questionnaire consisted of items such as age, spouse's age, number of children, economic status, education, occupation, number of times having sexual intercourses per month that was completed before the intervention. Sexual Dysfunctional Beliefs Questionnaire includes the most important myths and misconceptions in the sexual literature of men and women. This questionnaire consisted of 40 items which is used to investigate sexual dysfunction beliefs that are addressed as predisposing factors resulting in sexual dysfunction of women and men in clinical literature. The questionnaire is represented in two versions of male and female that each of which individually measures genderspecific beliefs. ${ }^{15}$ This questionnaire has been sensitized and localized based on Iranian culture by AbdolManafi et al and Dashtestannejad. ${ }^{14,16}$ The present version of this questionnaire consists of 33 items and includes 6 subscales (sexual conversations, affection primacy, motherhoodrelated beliefs, sexual desire and pleasure as sin beliefs, agerelated beliefs and body image beliefs). Answers are based on a five-item Likert scale from completely disagree to 
completely agree. Some items, which are items 1, 3, 22, 23 and 24, are scored in a reverse manner. Scoring the rest of the items is straightforward. This questionnaire was completed before the education and 2 weeks after the end of the last session by all the 50 women who have all received education program.

\section{The Education Program}

The program (the time and place of the class) was given to the women who were willing to participate in the study (all 50 women in our center accepted to participate). All of them were allocated to the education group, since we did not have a control group. Classes were held in a room at the health center. The intervention was held in six group discussion sessions. For this purpose, an education session lasting 60 to 90 mins was held every week. The number of participants in each class was between 6 and 12. The content of the sessions included the physiology and anatomy of the female reproductive system, hormonal changes in menopause, physical changes in menopause, management of symptoms and complications of menopause, the importance of having sexual intercourses during menopause, the recognition and management of sexual dysfunction beliefs, and education in relation to better sexual intercourses. At the end of each session, there was a question and answer time, and the participants' opinions were asked and their possible questions were answered. Also, at the end of the last session, the phone number and the email of researchers were provided to women in order to be in contact with them if they had any questions. The education was conducted by a trained midwife under the supervision of a midwifery faculty member.

\section{Ethical Consideration}

The present study was conducted under the supervision of Qazvin University of Medical Sciences. The study was approved by the Ethics Committee of this University (IR.QUMS.REC.1395.286). Participants signed the written informed consent. Also, this study was conducted in accordance with the Declaration of Helsinki.

\section{Data Analysis}

Data were analyzed by SPSS v.16. For this purpose, a paired $t$-test was used to compare the sexual dysfunction beliefs before and after the intervention. Descriptive tests (mean and frequency) were also used. The p-value of less than 0.05 was considered significant.

\section{Results}

A total number of 50 postmenopausal women participated in this study. All the participants were present in all the educational sessions, and in fact, no sample loss was observed.

The mean age of women participated in the study and their spouses were 53.26 and 55.96 years, respectively. Of all the 50 postmenopausal women in the study, 45 were illiterate or had a primary education degree. Most of the participants were housewives (84\%), and their spouses were farmers or retired $(70 \%)$. Seventy-two percent of women reported that their economic status to be at a desirable level. Most of the participants had children who lived with them at home $(90 \%)$. In relation to menopausal symptoms, 100 women had experienced vaginal dryness, and $70 \%$ of them stated that they had experienced hot flushes. The mean number of times having sexual intercourses before education was 2.2 times per month.

The mean score of sexual dysfunction beliefs before education was 114.58. The mean score of sexual dysfunction beliefs in postmenopausal women after education was significantly increased to 58.56 (p-value <0.001). The results also showed an improvement in the status of the subscales of sexual dysfunction beliefs. Accordingly, most positive changes were observed in the "age-related beliefs" subscale (Table 1).

\section{Discussion}

The sexual health of rural postmenopausal women and the role of dysfunctional beliefs in this regard are highly

Table I The Mean Score of the Subscales of Sexual Dysfunction Beliefs Before and After Education

\begin{tabular}{|l|l|l|l|}
\hline Variable & $\begin{array}{l}\text { Before } \\
\text { Education }\end{array}$ & $\begin{array}{l}\text { After } \\
\text { Education }\end{array}$ & p-value \\
\hline Sexual conversations & 14.3 & 6.9 & $\begin{array}{l}\text { t: } 23.37 \\
\text { p: } 001\end{array}$ \\
\hline $\begin{array}{l}\text { Sexual desire and } \\
\text { pleasure as sin beliefs }\end{array}$ & 23.64 & 12.48 & $\begin{array}{l}\text { t: } 31.74 \\
\text { p: } 001\end{array}$ \\
\hline Age-related beliefs & 20.74 & 7.72 & $\begin{array}{l}\text { t: } 44.39 \\
\text { p: } 000\end{array}$ \\
\hline Body image beliefs & 17.04 & 9.40 & $\begin{array}{l}\text { Wilcoxon test } \\
\text { p: } 001\end{array}$ \\
\hline Affection primacy & 21.38 & 11.80 & $\begin{array}{l}\text { t: } 20.36 \\
\text { p: } 001\end{array}$ \\
\hline $\begin{array}{l}\text { Motherhood-related } \\
\text { beliefs }\end{array}$ & 13.9 & 8.64 & $\begin{array}{l}\text { Wilcoxon test } \\
\text { p: } 001\end{array}$ \\
\hline
\end{tabular}


important, however, based on our searches, a similar study to the present study investigating the effect of a midwife-based group discussion education on sexual dysfunction beliefs in rural postmenopausal women was not found. Our searches showed two studies in which the effect of education on sexual dysfunction beliefs of pregnant women has been studied. In one study using a pre- and post-test design, 34 pregnant women were educated. In that study, participants were educated in 4 sessions each lasting for 60 mins. A researcher-made questionnaire with 13 questions was used in order to investigate the sexual dysfunction beliefs of pregnant women. Similar to the results of the present study, the results of this study showed that educating women led to a significant improvement in the sexual dysfunction beliefs in them. ${ }^{17}$ In another study in 2015 in Iran, Dashtestannezhad et al investigated the effect of a psychological program on the sexual dysfunction beliefs of young couples. Similarly, the Nobre and Pinto-Gouveia Sexual Dysfunctional Beliefs Questionnaire was used in order to investigate sexual dysfunction beliefs. Similar to the results of the current study, the results of Dashtestannejad et al showed that education could have positive effects on sexual dysfunctional beliefs. ${ }^{16}$

Although the results of the two above-mentioned studies were consistent with the results of the current study and showed that education has a positive effect on women's sexual dysfunction beliefs, the present study has two important features that make its results remarkable. The first feature is that the study was conducted on rural postmenopausal women. As the results showed, sexual dysfunction beliefs were highly prevalent among rural postmenopausal women before education. Given the low population of many villages in Iran, health service centers are usually available in bigger villages, and residents of low population villages do not normally receive these kinds of services. So, this can affect the health of women living in villages. Regarding the importance of the health of rural postmenopausal women, it is recommended that healthcare systems pay more attention to health promotion programs, including their sexual health by providing continuous programs. Another feature of the current study was the use of a midwife for educating the rural postmenopausal women. As the results showed, a midwife-based education had a significant and positive effect on sexual dysfunction beliefs. In Iran, midwives are trained during a 4-year course that mainly carried out at governmental universities. The results of this study showed that midwives could play a significant role in determining the health of rural menopausal women at the community level. In fact, it should be said that trained midwives can be used as educators at the community level to promote the health of postmenopausal women. Although in recent years with the use of the Family Physician Program, the role and presence of midwives at the community level in Iran has become more obvious, the potential seems to be much higher than the current situation and this issue should also be addressed by healthcare authorities. This issue can also be considered as a model in other developing countries in the region.

\section{Limitation}

The present study was a quasi-experimental pre-post design without a control group. This issue may decrease the power of our study.

\section{Conclusions}

Women's sexual health is very important during menopause, and healthcare systems should pay special attention to this issue. The present study showed that a midwife-based group discussion education could significantly reduce the sexual dysfunction beliefs among rural postmenopausal women. Therefore, it is recommended that more attention be paid to the role of midwives as an available and inexpensive personnel in healthcare planning for rural postmenopausal women. This matter can be very useful in developing countries with more financial and resource constraints. Given the lack of similar studies, it is strongly recommended that similar studies be repeated with this matter.

\section{Acknowledgments}

This study was extracted from a midwifery student dissertation by Maryam Sasanpoor; Master degree in midwifery counseling; the dissertation proposal was approved by Qazvin School of Nursing and Midwifery. We would like to thank all women for their cooperation. We also thank QUMS for their support.

\section{Disclosure}

The authors report no conflicts of interest in this work.

\section{References}

1. Kazemian S, Abbasian ZS. Experience of menopausal women in dealing with menopause: a qualitative study. J Qual Res Health Sci. 2016;5 (3):230-239.

2. Price SL, Storey S, Lake M. Menopause experiences of women in rural areas. $J$ Adv Nurs. 2008;61(5):503-511. doi:10.1111/j.13652648.2007.04522.x

3. Shobeiri F, Nazari M. Age at menopause and its main predictors among Iranian women. Int J Fertil Steril. 2014;8(3):267-272. 
4. Sagdeo MM, Arora D. Menopausal symptoms: a comparative study in rural and urban women. JK Sci. 2011;13(1):23-26.

5. Karma D, Saini S, Singh S. Quality of life among post-menopausal women in rural area of Punjab. JMSCR. 2018;06(1):32471-32477. doi:10.18535/jmscr/v6i1.168

6. Cumming GP, Mauelshagen AE, Parrish MH. Postmenopausal sexual dysfunction. Obstet Gynaecol. 2010;12(1):1-6. doi:10.1576/toag.12. 1.001.27551

7. Martínez J, Palacios S, Chavida F, Perez M. Urban-rural differences in Spanish menopausal women. Rural Remote Health. 2013;13:1865.

8. Heidari M, Ghodusi M, Rafiei H. Sexual self-concept and its relationship to depression, stress and anxiety in postmenopausal women J Menopausal Med. 2017;23(1):42-48. doi:10.6118/jmm.2017.23.1.42

9. Jain N, Mehra R, Goel P, Chavan BS. Sexual health of postmenopausal women in North India. J Midlife Health. 2019;10(2):70-74 doi:10.4103/jmh.JMH_38_18

10. Cagnacci A, Venier M, Xholli A, Paglietti C, Caruso S; ANGEL Study. Female sexuality and vaginal health across the menopausal age. Menopause. 2020;27(1):14-19. doi:10.1097/GME.0000000000001427

11. Agustus P, Munivenkatappa M, Prasad P. Sexual functioning, beliefs about sexual functioning and quality of life of women with infertility problems. J Hum Reprod Sci. 2017;10:213-220. doi:10.4103/jhrs.JHRS_137_16

12. Abdolmanafi A, Azadfallah P, Fata L, Roosta M, Peixoto MM, Nobre P. Sexual Dysfunctional Beliefs Questionnaire (SDBQ): translation and psychometric properties of the Iranian version. J Sex Med. 2015;12:1820-1827. doi:10.1111/jsm.12931
13. Nazarpour S, Simbar M, Ramezani Tehrani F, Alavi Majd H. Quality of life and sexual function in postmenopausal women. $J$ Women Aging. 2018;30(4):299-309. doi:10.1080/08952841.2017. 1395539

14. Santpure AS, Nagapurkar SN, Giri PA, Bhanap PL. Female sexual dysfunction amongst rural postmenopausal woman. Int $J$ Reprod Contracept Obstet Gynecol. 2016;5:4385-4389. doi:10.18203/23201770.ijrcog20164349

15. Nobre P, Gouveia JP, Gomes FA. Sexual dysfunctional beliefs questionnaire: an instrument to assess sexual dysfunctional beliefs as vulnerability factors to sexual problems. Sex Relationsh Ther. 2003;18(2):171-204. doi:10.1080/1468199031000061281

16. Dashtestannejad A, Eshghi R, Afkhami E. Effectiveness of premarital sex education on sexual dysfunctional beliefs of couples, Isfahan. PCNM. 2015;4(2):14-22.

17. Mohamadi S, Ozgoli G, Alizadeh S, Borumandnia N, Abbas A. The effect of modification of dysfunctional sexual beliefs on promotion of quality of pregnant women sexual life in Besat hospital. Res Med. 2017;41(3):166-174.

\section{Publish your work in this journal}

The International Journal of Women's Health is an international, peerreviewed open-access journal publishing original research, reports, editorials, reviews and commentaries on all aspects of women's healthcare including gynecology, obstetrics, and breast cancer. The manuscript management system is completely online and includes a very quick and fair peer-review system, which is all easy to use. Visit http://www.dovepress.com/testimonials.php to read real quotes from published authors. 